\title{
Determination of Zinc Sulfide Solubility to High Temperatures
}

\author{
Carolina Figueroa Murcia, Diana; Fosbøl, Philip Loldrup; Thomsen, Kaj; Stenby, Erling Halfdan
}

Published in:

Journal of Solution Chemistry

Link to article, DOI:

10.1007/s10953-017-0648-1

Publication date:

2017

Document Version

Peer reviewed version

Link back to DTU Orbit

Citation (APA):

Carolina Figueroa Murcia, D., Fosbøl, P. L., Thomsen, K., \& Stenby, E. H. (2017). Determination of Zinc Sulfide Solubility to High Temperatures. Journal of Solution Chemistry, 46(9-10), 1805-1817.

https://doi.org/10.1007/s10953-017-0648-1

\section{General rights}

Copyright and moral rights for the publications made accessible in the public portal are retained by the authors and/or other copyright owners and it is a condition of accessing publications that users recognise and abide by the legal requirements associated with these rights.

- Users may download and print one copy of any publication from the public portal for the purpose of private study or research.

- You may not further distribute the material or use it for any profit-making activity or commercial gain

- You may freely distribute the URL identifying the publication in the public portal

If you believe that this document breaches copyright please contact us providing details, and we will remove access to the work immediately and investigate your claim. 


\title{
Determination of Zinc Sulfide Solubility to High Temperatures
}

Diana Carolina Figueroa Murcia ${ }^{1}$, Philip L. Fosb $\left.\varnothing\right|^{1}$, Kaj Thomsen ${ }^{1 *}$, Erling H. Stenby ${ }^{2}$

${ }^{1}$ Center for Energy Resources Engineering, CERE, Department of Chemical and Biochemical Engineering, Technical University of Denmark, DTU

${ }^{2}$ Department of Chemistry, Technical University of Denmark, DTU

* Corresponding author:

Kaj Thomsen

kth@kt.dtu.dk

\begin{abstract}
A new experimental set-up and methodology for the measurement of ZnS solubility in aqueous solutions at 40, 60 and $80{ }^{\circ} \mathrm{C}$ (atmospheric pressure) is presented. The methodology implemented includes the preparation of the samples in a reduced oxygen atmosphere, particle size analysis of $\mathrm{ZnS}$, quality control of the analytical technique and evaluation of equilibration time.
\end{abstract}

ZnS solubility analyses were run at prolonged times (up to 11 days) to ensure that equilibrium conditions were met. The equilibration time was explored at three temperatures $\left(40{ }^{\circ} \mathrm{C}, 60{ }^{\circ} \mathrm{C}\right.$, and $80{ }^{\circ} \mathrm{C}$ ) observing small variations in the time required to reach the solid liquid equilibrium conditions at each temperature. Equilibrium was reached within 72 hours. The concentration of zinc and of total sulfur was determined using Inductively Coupled Plasma Optical Emission Spectroscopy (ICP-OES). The experimental solubility data show an exponential dependency of the solubility with respect to temperature. An increase of $40{ }^{\circ} \mathrm{C}$ results in an increase of roughly 12 times for the solubility of ZnS.

Key words: Zinc sulfide; Solubility in aqueous solutions; HP/HT reservoirs; Scaling materials. 


\section{Introduction}

The increasing demand for oil has led to exploration of high pressure and high temperature reservoirs (HPHT). However, these reservoirs are not well known and their economically and technically feasible exploration/operation/production requires understanding of new issues, such as exotic scaling. Scaling in both wellbore and surface equipment represents a safety and production loss issue due to pipe blockage. It may jeopardize the continuous exploration of the reservoir. Then, it is important to understand and account for the impact of scale formation during the life time of an oil reservoir.

Exotic Scale formation refers to precipitation of $\mathrm{ZnS}, \mathrm{PbS}$ and FeS [1] due to changes in pressure and temperature when brine, oil and gas is transported from underground to the surface. To reduce the risk associated with scaling it is important to determine the solubility of these three sulfides at the operating temperatures and pressures, i.e. temperatures up to $200{ }^{\circ} \mathrm{C}$ and pressures up to 1000 bar.

Several authors have studied and measured the solubility of $\mathrm{ZnS}$ in aqueous solutions at temperatures ranging from $18{ }^{\circ} \mathrm{C}$ to $350{ }^{\circ} \mathrm{C}$. Generally, these solubility experiments were performed using different sources of Zinc Sulfide (ZnS). It is important to remember that ZnS exists in two crystalline forms: Sphalerite and Wurtzite. Sphalerite is the cubic crystal form of ZnS and it is thermodynamically stable at standard conditions while wurtzite (hexagonal crystal form) is thermodynamically stable at temperatures above $1035{ }^{\circ} \mathrm{C}$ [2]. These crystalline forms present different solubility values.

In the study by [3] precipitated ZnS was used, obtained by bubbling $\mathrm{H}_{2} \mathrm{~S}$ through a solution of $\mathrm{ZnCl}_{2}$. No further analysis to confirm the crystal structure of the solid was carried out. By this insitu precipitation of ZnS, different types of solids with different properties can be produced. The solubility of ZnS precipitated from alkaline medium (identified by [3] as $\beta$ ZnS) is about 4.6 times higher than the solubility of ZnS precipitated from acidic medium (identified by Barrett and Anderson as $\alpha$ ZnS). It was indicated by [4] that their solubility measurements were slightly higher for the precipitated solid form than the solubility of the natural occurring sphalerite as a 
consequence of the presence of another crystalline form of $\mathrm{ZnS}$ : Wurtzite. They assumed that wurtzite was present in such small quantities that a XRD analysis could not detect it. They compared their measured solubility values of natural and of precipitated sphalerite and concluded that the solubility of natural sphalerite is lower than that of the precipitated form. Their hypothesis was that the difference in solubility was due to the presence of fine particles or another form of ZnS.

The solubility of $\mathrm{ZnS}$ at $100^{\circ} \mathrm{C}$ and $150^{\circ} \mathrm{C}$ was measured by [5]. The measurements were carried out in a titanium flow-through hydrothermal reactor. As starting material, they used ZnS confirmed to be pure sphalerite structure using X-Ray Diffraction (XRD). The ZnS was recrystallized in a furnace at $850{ }^{\circ} \mathrm{C}$ together with pure sulfur for 3 weeks. Afterwards the material was cooled down in the furnace and as result they obtained larger particles of ZnS (approximately $0.1 \mathrm{~mm}$ across). The water used in the solubility experiment was in this case boiled in an ultrasonic bath under vacuum and then Argon was bubbled through. The aqueous solution was saturated with $\mathrm{H}_{2} \mathrm{~S}$ at a partial pressure of approximately 0.7 bar $\mathrm{H}_{2} \mathrm{~S}$ above atmospheric pressure. The samples were withdrawn from the main vessel and part of the water was evaporated from the samples. The evaporation was done in order to have concentrations above the detection limits of the applied analytical techniques. The total sulfur content was determined by iodimetric back titration with sodium thiosulphate. The determination of the concentration of zinc was achieved by flame atomic absorption spectroscopy.

The analytical techniques and the experimental procedures documented in literature for measuring the solubility of $\mathrm{ZnS}$ are widely diverse, which is a contributing factor for the observed scatter in the published data. The zinc content was analyzed using atomic absorption spectroscopy $[3,5-8]$

The solubility of mineral and precipitated ZnS was measured by [9]. The author did not use degassed water, which could lead to the formation of oxidized sulfate species. These oxidized species give a higher zinc concentration. Thus, the measured value is a combination of the $\mathrm{ZnS}$ solubility and the solubility of the oxidized sulfate species. Furthermore, the solubility was measured using conductivity as analytical technique. Conductivity is not a zinc selective 
technique as contaminants and other ions in the solution also contribute to the measured conductivity value. The measured conductivity values include the impurities present in either the aqueous solution or dissolved from the mineral/precipitated form of ZnS. Moreover, the use of both mineral and precipitated ZnS was employed by [9]. Differences were observed for the solubility measurements when using mineral ZnS and precipitated ZnS. The author noticed that the solubility of mineral ZnS is lower than that of precipitated ZnS [9].

The gravimetric technique was employed in this studies [10-12]. The solubility of ZnS was determined in water at temperatures between 200 and $300{ }^{\circ} \mathrm{C}$ (no clear information about the experimental pressure is given) [10]. Oxygen was removed from the water by stripping with pure nitrogen. The solute was light brown colored mineral ZnS. The solubility was determined by a gravimetric method removing crystals from the bomb and then weighed in a micro-balance after each run. The solubility data presented by [10] show no significant temperature dependency between $194{ }^{\circ} \mathrm{C}$ and $300{ }^{\circ} \mathrm{C}$. It is suggested that the value determined corresponds to the solubility of zinc oxide ( $\mathrm{ZnO}$ ) [10]. A possible explanation for this unexpected tendency may be the presence of impurities in the type of solute used by [10]. Thus, the value of solubility reported may correspond to the solubility of other species rather than ZnS, e.g. ZnO [10]. The gravimetric method applied by [10] is questionable as well, since it is not the most suitable for this type of experiments due to its low accuracy for sparingly soluble materials [10]. The precision of the method was questioned by [11] who also implemented this method for the determination of ZnS solubility. It was claimed by [10] that $20 \mathrm{mg}$ of the solid were dissolved in $20 \mathrm{~cm}^{3}$ of water, in the bomb. There is no information about the accuracy of the measurements nor the sensitivity of the scale used.

A colorimetric measurement technique was implemented by [13]. The solubility of ZnS was measured in water at temperatures from $110{ }^{\circ} \mathrm{C}$ up to $350{ }^{\circ} \mathrm{C}$. The measurements were carried out at the corresponding water vapor pressure at each temperature. The ZnS was prepared insitu using a solution of zinc acetate and $\mathrm{H}_{2} \mathrm{~S}$ (purity 99.2\%). The solubility measurements were carried out in an autoclave using degassed water. The zinc present in the aqueous solution was analyzed by means of colorimetry using dithizone. The solubility data published by [13] show a 
slight dependency on temperature. There is no information regarding the pore size of the filter plug installed in the experimental set-up. Potentially in this case, the data reported as ZnS solubility could contribute to the concentration of suspended fine particles in the apparently saturated solution.

The solubility of radioactive $\mathrm{ZnS}$ was measured in a bomb at $130 \pm 5^{\circ} \mathrm{C}$ at pressures between 275-345 bar by [14]. The solubility was determined using the Zn65 as a tracer and measuring the gamma-radiation intensity with a scintillation detector. It is mentioned that different zones at different temperatures were detected in the bomb. The sensitivity of the tracer method was questioned by the author, suggesting the radiation of the sample was weak and therefore the data obtained is doubtful [14].

The solubility of $\mathrm{ZnS}$ in aqueous solution measured using the polarography technique was employed in [15]. He reported solubility values at $25{ }^{\circ} \mathrm{C}$ and $100{ }^{\circ} \mathrm{C}$ at 6.8 and 34 bar respectively in pure water. An increase of $\mathrm{ZnS}$ solubility is observed as temperature and pressure increase. However, in this case the individual influence of temperature or pressure cannot be discussed [15].

The majority of the analytical methods here mentioned do not have very low detection limits and therefore the accuracy of the solubility determination is questionable. Thus, both the purity of the sample and the experimental method needs to be carefully selected to assure reliability and precision of the experimental data.

Further investigation of ZnS solubility is essential to increase the confidence in the experimental measurements. These measurements form the basis of advanced models, e.g. Extended UNIQUAC model [16], MULTISCALE ${ }^{\circledR}$ [17] and ScaleChem [18] used in prediction of scale formation. Thus, reliability of solubility measurements is vital to improve the accuracy of models.

We present a new experimental set-up and an improved methodology to perform solubility measurements of $\mathrm{ZnS}$ at temperatures up to $80^{\circ} \mathrm{C}$ and atmospheric pressure. We found that equilibration time plays an important role in obtaining reliable data. In addition, we compare 
our results to available published data and we demonstrate that the developed experimental procedure eliminates the main limitations of previous ZnS solubility measurements. These limitations include lack of elimination of oxygen from the aqueous phase, detection limits of the analytical technique, and efficiency of the filtration step.

\section{Experimental set-up}

Our experimental set-up designed for measuring the solubility of sparingly soluble salts such as ZnS is shown in Fig. 1. The system consists of 3 key parts: (1) an equilibrium cell (Fig. 1b), transport of sample at constant temperature (Fig. 1d) and filtration at constant temperature (Fig. 1e).

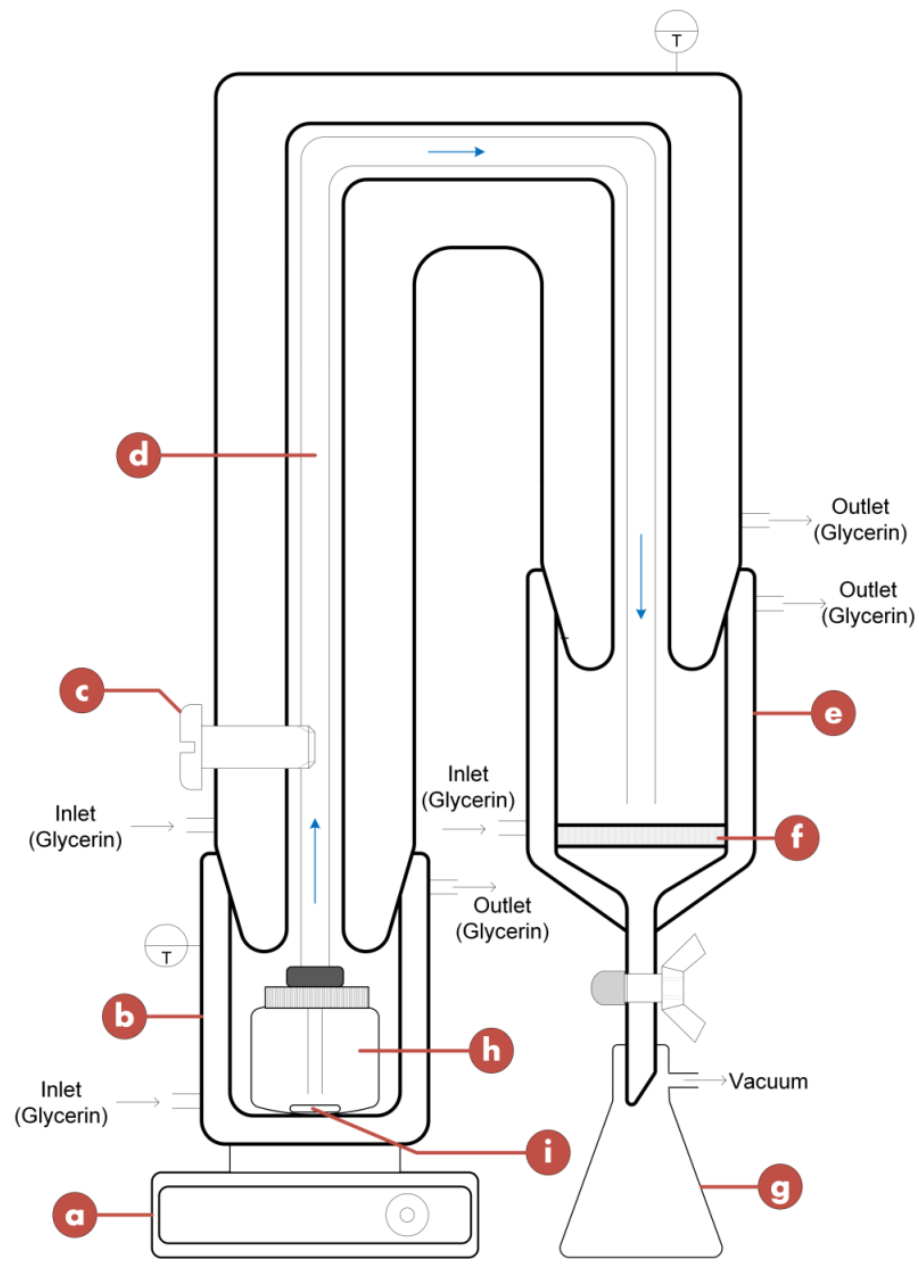

Fig. 1 Experimental set-up for measurements of ZnS. (a) Stirring plate, (b) equilibration cell, (c) Teflon screw, (d) transport of sample at constant temperature, (e) filter chamber, (f) porous body, (g) side-arm flask, (h) vial and (i) stirring bar 
The set-up runs at constant temperature by means of a thermostatic bath using glycerin as heat-transfer fluid. The filter chamber (Fig. 1e) is a double walled chamber that contains a porous body (Fig. 1f) made of fritted glass of porosity $(10-16 \mu \mathrm{m})$.

\subsection{Materials description}

The experiments were performed using ZnS powder of 99.99\% purity (from Sigma-Aldrich) and with a particle size of $10 \mu \mathrm{m}$. The characteristics of this solid were analyzed using state-of-theart analytical techniques. The particle size distribution of the ZnS powder was verified by means of laser diffraction analysis. The ZnS crystal structure was confirmed by means of X-Ray Diffraction (XRD) and its elemental composition was determined using a Scanning Electron Microscope (SEM).

\subsubsection{Purity of the ZnS material used}

We performed an X-ray diffraction analysis (powder XRD) which indicates the presence ZnS in its cubic form. It further shows that the ZnS crystals do not undergo any changes after days of being under experimental conditions.

The elemental composition was carried out using SEM analysis and it is shown in Table 1 . The results confirm the presence of zinc and sulfur as major components. The impurities present in the $\mathrm{ZnS}$ can be considered negligible. The presence of these impurities is also doubtful since the majority of peaks overlap Zn and S.

Table 1 Elemental analysis for ZnS material used using SEM

\begin{tabular}{lrrrrr}
\multicolumn{7}{c}{ Elements (Weight \%) } \\
\hline Statistics & Zn & S & O & Na & Cu \\
\hline Max & 62.57 & 30.95 & 2.03 & 9.47 & 1.90 \\
Min & 60.57 & 26.54 & 1.20 & 3.55 & 1.52 \\
Average & 61.58 & 28.42 & 1.54 & 6.74 & 1.72 \\
Standard Deviation & 0.99 & 1.98 & 0.40 & 2.67 & 0.15 \\
\hline
\end{tabular}

The elemental analysis demonstrates that the composition corresponds to $\mathrm{ZnS}$ and the impurities do not have a significant effect on the solubility measurements of ZnS. 
The number of areas analyzed during the SEM analysis was 4. The standard deviation obtained for these measurements is considered low and acceptable with respect to the average value obtained. Thus, no more measurements were carried out to determine the composition of ZnS. Our intention using the SEM was to confirm the presence of $\mathrm{Zn}$ and $\mathrm{S}$ as major components, rather than providing the exact quantitative composition of $\mathrm{ZnS}$

The aqueous samples were prepared using ultra-pure water (resistivity 18.2 M $\Omega$ ) degassed with nitrogen (purity 99.999\%) [19]. The concentration of dissolved oxygen was monitored using an oxygen electrode. The oxygen removal process was stopped when the oxygen level was less than $0.01 \mathrm{mg} / \mathrm{L}$ (lowest detection level of the electrode). The $\mathrm{ZnS}$ in solid form was equilibrated with degassed ultra-pure water at reduced oxygen atmosphere in a glove box using nitrogen (purity 99.999\%). This is an important step as ZnS is susceptible to oxidation in presence of oxygen $[12,20]$. Oxidation of the sample leads to formation of $\mathrm{ZnO}$.

\section{Methodology}

This section describes the methodology developed for solubility measurements of salts with very low solubility in water, such as $\mathrm{ZnS}, \mathrm{PbS}$ and FeS. This methodology is demonstrated for $\mathrm{ZnS}$ and it addresses many of the uncertainties of previous experiments: evaporation of unknown amounts of water at high temperatures, identity of the crystalline form of the investigated sample, the filter pore size and the particle size, the purity of the sample, impact of oxygen and other impurities.

In this study, the determination of $\mathrm{ZnS}$ solubility was carried out at temperatures up to $80^{\circ} \mathrm{C}$ and atmospheric pressure. In all our experiments, the surface of the sample was covered with a layer of insoluble silicon oil to minimize evaporation, similar to the work of [21]. Solubility measurements at $96{ }^{\circ} \mathrm{C}$ were performed but the evaporation of the aqueous phase was significant. In order to avoid the issues related to high temperatures (e.g. evaporation, constant pressure conditions) we are currently developing a new high pressure/high temperature equipment. 
Afterwards, the sample was placed in a polypropylene vial (see Fig. 1h) instead of a glass vial, to reduce the risk of contamination with interfering ions in the aqueous solution. Then, silicon oil was added to the aqueous solution to avoid vapor formation of the solution and evaporation of $\mathrm{H}_{2} \mathrm{~S}$ from the solution [21]. The vial was immersed in the equilibrium cell (Fig. 1b) filled with glycerin and connected to a thermostatic bath until equilibrium is attained. The sample is stirred continuously using a stirring plate (Fig. 1a). The vial (Fig. 1h) is connected to the sampling hose (Fig. 1d) and sealed using a Teflon screw (Fig. 1c) to avoid the presence of oxygen in the sample. Stirring was stopped approximately 3 hours before sampling to allow ZnS particles to settle down.

After solid-liquid equilibrium was attained, the suspension was filtered at constant temperature in the filtration chamber (Fig. 1e). The filter is custom made with a heating jacket using a temperature equal to the equilibration temperature. This guarantees no alteration of the equilibration conditions of the solution. A filter paper with a pore size of $0.22 \mu \mathrm{m}$ was used. This is a key feature of the developed experimental set-up which maintains success of the sampling.

After filtration, the solution is diluted immediately with ultra-pure water (Fig. 1g). The dilution of the sample takes place in the side-arm flask with a previously weighed amount of ultra-pure water. This dilution is carried out to avoid precipitation of the solid phase from the saturated solution. The dilution takes place at room temperature.

Afterwards, a set of samples were withdrawn from the diluted solution and the concentration of zinc and total sulfur was determined by Inductively Coupled Plasma Optical Emission Spectroscopy (ICP-OES).

The excess solid was collected from the vial (see Fig. 1h), dried in a vacuum oven (at $105^{\circ} \mathrm{C}$ ) and the crystal structure was analyzed by XRD. 


\section{Results and discussions}

The results of the experimental determination of ZnS solubility are presented in two sections: First the equilibration time results are presented as concentration of zinc and total sulfur versus time. Then, the solubility of $\mathrm{ZnS}$ at different temperatures ranging from $40^{\circ} \mathrm{C}$ up to $80^{\circ} \mathrm{C}$ is presented.

\subsection{Particle size distribution of the ZnS source material}

The distribution of the ZnS source material particle size used in this work was determined in two different ways: 1 . in powder (dry) and 2. in an aqueous dispersed form (dispersion). This was carried out in order to determine the correct pore size for the filtration step. This particle size distribution analysis was performed using the laser diffraction method [22]. The results are presented in Fig. 2 as the volume density (\%) versus the particle size (logarithmic scale).

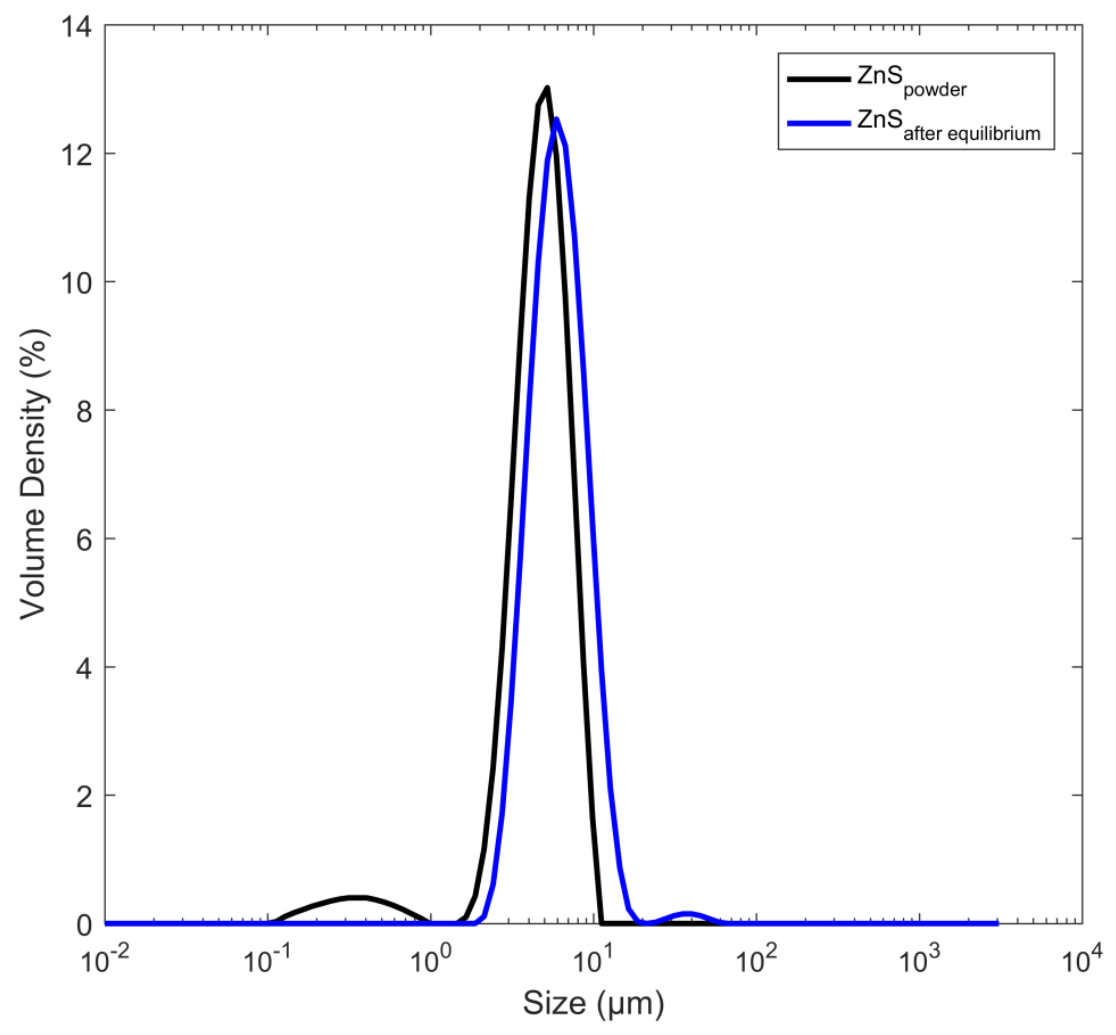

Fig. 2 Particle size distribution for ZnS 
Fig. 2 shows that the ZnS powder used in the experiments has a particle size distribution between 0.11 to $9.86 \mu \mathrm{m}$. The majority of the particles (13.02\%) have a particle size of $5.21 \mu \mathrm{m}$. The vast majority of the particles are smaller than $10 \mu \mathrm{m}$ as specified by the supplier. For the powder, $98.87 \%$ of the particles have a particle size greater than the selected filter pore size $(0.22 \mu \mathrm{m})$. A more useful scenario is the measurement of the particle size of ZnS dispersed in the saturated solution. This analysis provides the particle size distribution of the sample before filtration. In this case the particle size is distributed between $2.13 \mu \mathrm{m}(0.11 \%)$ and $58.9 \mu \mathrm{m}$ $(0.02 \%)$ with a maximum at $12.53 \%$ that corresponds to a particle size of $5.92 \mu \mathrm{m}$. These findings are in agreement with the result for the powder. Fig. 2 shows that the majority of the particles are smaller than $10 \mu \mathrm{m}$ and $99.99 \%$ of the particles have a particle size above $0.22 \mu \mathrm{m}$ (filter paper pore size). Thus, the particle size analysis confirmed that the majority of the particles are larger than the pore size of the used filter paper.

The particle size distribution analysis provided valuable information for choosing the correct filter pore size for filtration. If the filter pore size is chosen arbitrarily, the chance of fine particles passing through the filter is very high. Then, the determination of the ZnS solubility would be erroneous as the concentration of $\mathrm{Zn}$ and $\mathrm{S}$ would include the fine particles suspended in the "saturated solution" as mentioned by [4].

\subsection{Equilibration time determination}

This section discusses the importance of equilibration time when determining the solubility of ZnS at temperatures up to $80{ }^{\circ} \mathrm{C}$. The equilibration time represents the time needed to reach equilibrium between the solid and the liquid phases and it varies with respect to temperature and the source of ZnS. Therefore, the experimental analysis of equilibration time is very important to assure experimental reproducibility and accuracy.

There is no agreement regarding the equilibration times for ZnS solubility suggested in the literature. It was indicated by [8] in their experiments that the solubilization period is greater than 48 hours. They did not provide any reason why they decided on using this equilibration time. The equilibration time was estimated based on the $\mathrm{pH}$ of the solutions by $[3,6]$. They 
estimated that equilibrium is attained in hours (in saline solutions), based on the time required for the solution to reach a constant value of $\mathrm{pH}$. They mentioned that the equilibration time depends on the starting material. They found that the equilibration time is achieved faster when using precipitated material than when using the mineral forms $[3,6]$.

The experiments performed by [10] were run up to 150 hours (roughly 6 days). The author did not explore the results at extended times. His results indicate that equilibrium was not reached and therefore no influence of temperature was observed [10]. The equilibration time was determined between few days (at high temperatures) and up to 2 weeks (at low temperatures) for their experiments of $\mathrm{ZnS}$ and $\mathrm{PbS}$ at 300 to $500{ }^{\circ} \mathrm{C}$ and 1000 bars by [12]. It was observed that equilibrium is attained at around 50 to 60 hours [14].

Figure 3 shows the concentration of zinc and the concentration of total sulfur as a function of time for temperatures between $40{ }^{\circ} \mathrm{C}$ and $80{ }^{\circ} \mathrm{C}$. We assume that all zinc is present as zinc ion $\left(\mathrm{Zn}^{2+}\right)$.

Fig. $3 c$ shows that the concentration of zinc increases during the first 3 days. Then it reaches a plateau corresponding to equilibrium. Fig. $3 a$ and Fig. 3b show that the concentration of zinc slightly fluctuates with respect to time. However the concentration of total sulfur remains constant along the time interval studied. The scattering observed in the data could be due to presence of colloidal particles present in the filtrate that passed through the filter paper. The presence of colloidal particles might contribute to the solubility values of $\mathrm{ZnS}$

The equilibration time is observed to vary depending on temperature and it is apparently shorter at higher temperatures. It can be observed from Fig 3 and Table 2 that the equilibration time in this interval of temperature $\left(40{ }^{\circ} \mathrm{C}\right.$ to $\left.80^{\circ} \mathrm{C}\right)$ required is minimum 3 days. 

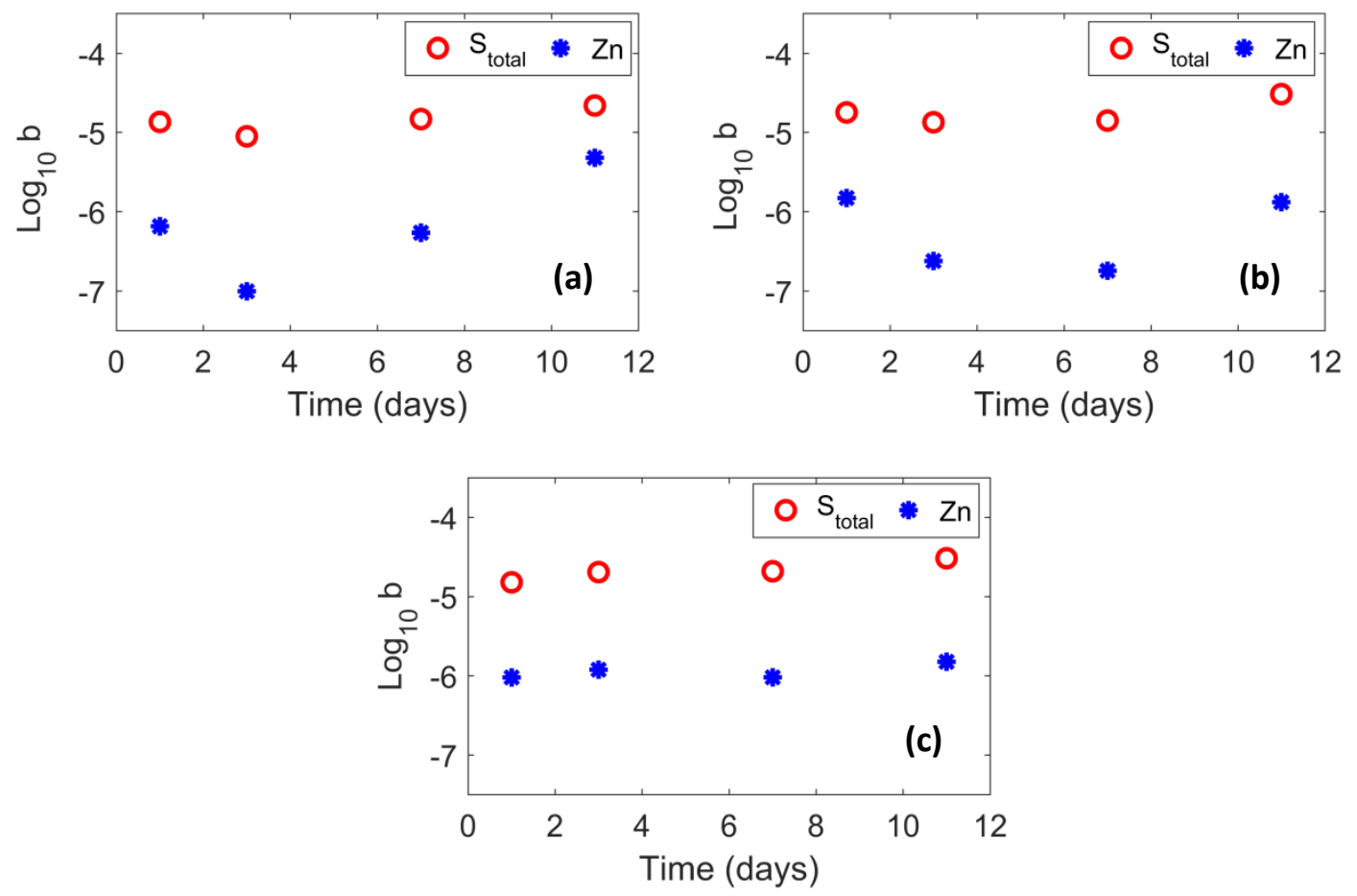

Fig. 3 Determination of the equilibration time for ZnS solubility in molality $b\left(\mathrm{~mol}^{\circ} \mathrm{kg}_{\text {water }}{ }^{-1}\right.$ ) versus temperature (a) $40{ }^{\circ} \mathrm{C}$ (atmospheric pressure), (b) $60{ }^{\circ} \mathrm{C}$ (atmospheric pressure) and (c) $80^{\circ} \mathrm{C}$ (atmospheric pressure).

The results described above are based on the behavior of the zinc concentration. The concentration of total sulfur remains almost constant over the intervals of time analyzed; suggesting that the equilibration time is achieved in a matter of hours. Fig. 3 shows that up to 10 days, the concentration of total sulfur is in some cases hundreds of times higher than the concentration of zinc. This difference between zinc and total sulfur concentration reduces over time at $40{ }^{\circ} \mathrm{C}$ and 11 days when the concentration or total sulfur is just five times higher than the concentration of zinc. This behavior is not observed at higher temperatures analyzed $\left(60{ }^{\circ} \mathrm{C}\right.$ $\left.-80^{\circ} \mathrm{C}\right)$.

This difference between the concentration of zinc and total sulfur could be due to the presence of byproducts in the $\mathrm{ZnS}$ or formation of other products during the solubilization process. It was mentioned by [23] that a soluble species $\mathrm{Zn}(\mathrm{HS})_{n}$ could be present in the aqueous solution. They also observed an excess of total sulfur even though sulfur was added in stoichiometric 
quantities [23]. The formation of complexes has been discussed by several authors; nonetheless the existence of those complexes cannot be easily proved [4, 5, 8, 24]. It was found by [24] in their studies on the formation of sphalerite at low temperature $\left(25^{\circ} \mathrm{C}\right)$ in saline solutions $(0.545$ $\mathrm{mol} \cdot \mathrm{L}^{-1} \mathrm{NaCl}$ ) and neutral $\mathrm{pH}$ (controlled by adding $5 \mathrm{mmol} \cdot \mathrm{L}^{-1}$ of acetate) a complex with stoichiometry of $3 \mathrm{~S}$ and $2 \mathrm{Zn}$. They claimed the presence of molecular clusters of $\mathrm{ZnS}$ in solution [24].

It can be concluded that the time required to reach equilibrium conditions is minimum 3 days at temperatures above $40{ }^{\circ} \mathrm{C}$. The exact time cannot be set as it is very hard to identify a clear trend of the zinc concentration versus time as demonstrated in Fig. 3

Table 2 Solubility data for $\mathrm{ZnS}$ at temperatures between $40^{\circ} \mathrm{C}$ and $80^{\circ} \mathrm{C}$ at atmospheric pressure equilibration times between 1 and 11 days. The concentration corresponds to the average of the data points reported.

\begin{tabular}{|c|c|c|c|c|c|c|c|c|}
\hline \multirow{4}{*}{$\begin{array}{l}\begin{array}{l}\text { Eq. time } \\
\text { (days) }\end{array} \\
11\end{array}$} & \multirow{2}{*}{$\begin{array}{l}\text { Temp. } \\
\left.\text { ( }{ }^{\circ} \mathrm{C}\right) \\
40\end{array}$} & \multicolumn{3}{|c|}{$\begin{array}{c}\text { Zn concentration } \\
{\left[\mathrm{mol} \cdot \mathrm{kg}^{-1} \mathrm{H}_{2} \mathrm{O}\right] \times 10^{8}}\end{array}$} & \multirow{2}{*}{$\begin{array}{r}\begin{array}{c}\text { Data } \\
\text { points }\end{array} \\
4\end{array}$} & \multicolumn{2}{|c|}{$\begin{array}{l}\mathrm{S} \text { total concentration } \\
{\left[\mathrm{mol} \cdot \mathrm{kg}^{-1} \mathrm{H}_{2} \mathrm{O}\right] \times 10^{6}}\end{array}$} & \multirow{2}{*}{$\begin{array}{r}\begin{array}{c}\text { Data } \\
\text { points }\end{array} \\
4\end{array}$} \\
\hline & & 65.27 & \pm & 18.8 & & $13.54 \pm$ & 0.1 & \\
\hline & 60 & 148.03 & \pm & 1.5 & 3 & $17.84 \pm$ & 0.2 & 3 \\
\hline & 80 & 95.36 & \pm & 48.1 & 3 & $15.09 \pm$ & 0.1 & 5 \\
\hline \multirow[t]{3}{*}{3} & 40 & 9.91 & \pm & 0.6 & 4 & $8.91 \pm$ & 0.7 & 5 \\
\hline & 60 & 23.91 & & 2.9 & 4 & $13.40 \pm$ & 0.1 & 4 \\
\hline & 80 & 119.52 & \pm & 16.3 & 3 & $20.30 \pm$ & 9.7 & 3 \\
\hline \multirow[t]{3}{*}{7} & 40 & 54.14 & \pm & 17.3 & 6 & $14.71 \pm$ & 0.7 & 3 \\
\hline & 60 & 18.00 & \pm & 0.9 & 3 & $14.09 \pm$ & 0.7 & 4 \\
\hline & 80 & 95.66 & \pm & 4.2 & 4 & $20.81 \pm$ & 1.2 & 3 \\
\hline \multirow[t]{3}{*}{11} & 40 & 477.00 & \pm & 147.4 & 4 & $21.82 \pm$ & 1.2 & 4 \\
\hline & 60 & 131.26 & \pm & 68.9 & 4 & $14.09 \pm$ & 0.7 & 4 \\
\hline & 80 & 150.52 & \pm & 0.8 & 3 & $30.40 \pm$ & 12.9 & 3 \\
\hline
\end{tabular}




\subsection{Effect of temperature on ZnS solubility}

Fig. 4 shows the effect of temperature on the solubility of $\mathrm{ZnS}$ at temperatures between $40{ }^{\circ} \mathrm{C}$ $400{ }^{\circ} \mathrm{C}$ and varying pressures. The $\mathrm{ZnS}$ solubility data of this work reported in Fig. 4 corresponds to the concentration of zinc and 3 days of equilibration at atmospheric pressure. The solubility data are presented in Table 2.

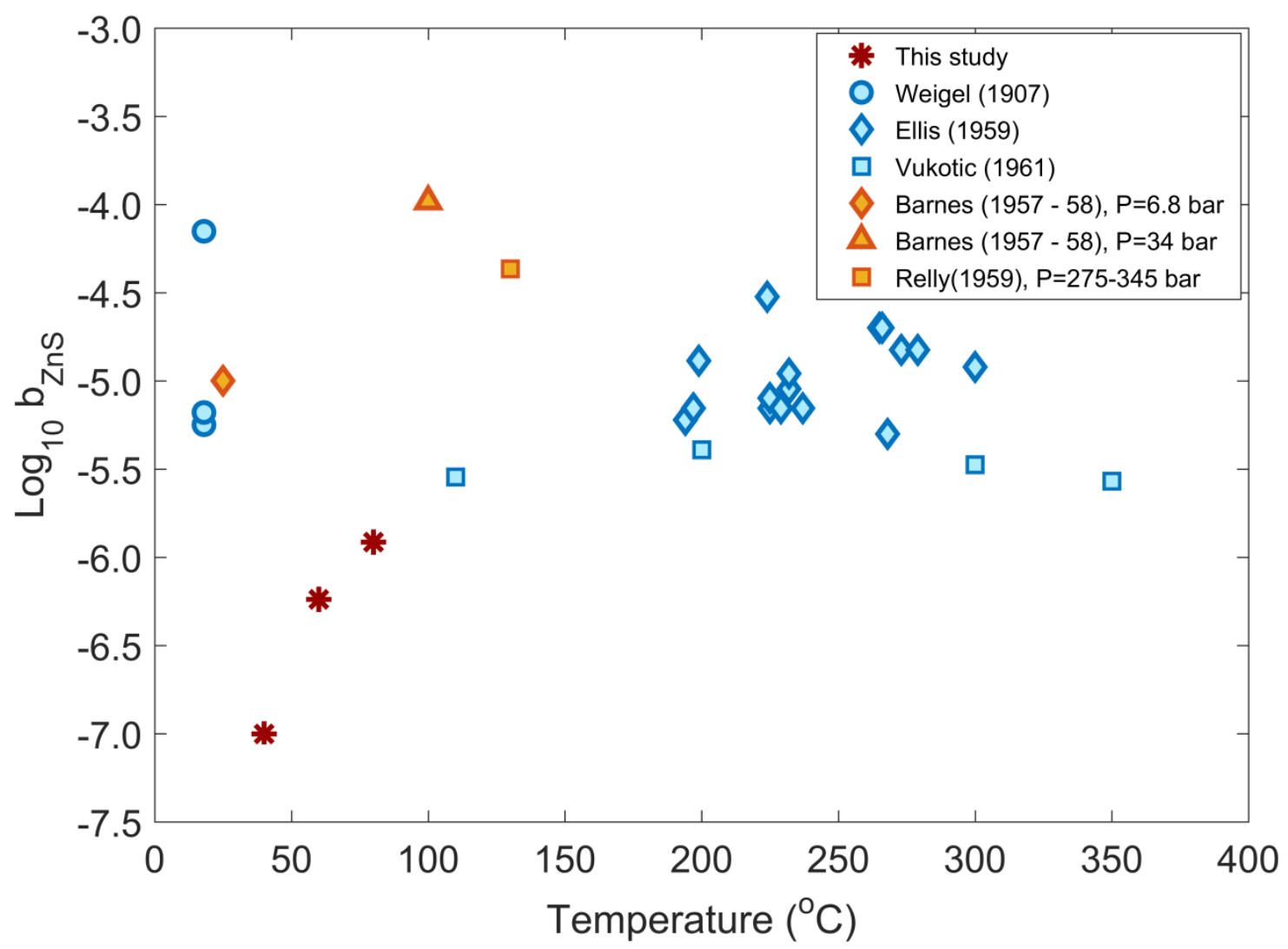

Fig. $4 \mathrm{ZnS}$ solubility in molality $b_{\mathrm{ZnS}}\left(\mathrm{mol} \cdot \mathrm{kg}_{\text {water }}{ }^{-1}\right)$ versus temperature

Fig. 4 indicates that the solubility of ZnS exponentially increases with temperature between 40 ${ }^{\circ} \mathrm{C}$ and $80{ }^{\circ} \mathrm{C}$. An increase of $40{ }^{\circ} \mathrm{C}$ results in an increase of roughly 12 times for the solubility of ZnS.

Fig. 4 also shows published ZnS solubility by $[9,10,13-15]$. The pressure conditions of the studies by $[9,10]$ at which the solubility data were obtained are not specified. The pressure conditions for [13] experiments correspond to the water vapor pressure at each temperature. 
This diagram shows that our measured ZnS solubility at 40 and $60{ }^{\circ} \mathrm{C}$ are $10-100$ times lower than previously published data. The reason for this is discussed below.

The solubility data presented by [10] show no significant temperature dependency between $194{ }^{\circ} \mathrm{C}$ and $300{ }^{\circ} \mathrm{C}$ as observed in Fig. 4. A possible explanation for this unexpected tendency may be the presence of impurities in the type of solute used by [10] or the presence of oxygen in the bomb that lead to formation of $\mathrm{ZnO}$ as suggested by [10].

The solubility data published by [13] in Fig. 4 show a slight dependency on temperature. An increase in solubility is observed from $110{ }^{\circ} \mathrm{C}$ until $200{ }^{\circ} \mathrm{C}$, reaching at this point a maximum. Beyond $200{ }^{\circ} \mathrm{C}$ the solubility of ZnS tends to decrease.

An increase of ZnS solubility is observed (see Fig. 4) as temperature and pressure increase for the solubility data published by [15]. However, in this case the individual influence of temperature or pressure cannot be discussed, since both parameters were modified during the experiments.

The ZnS solubility data presented by different authors in Fig. 4 are highly scattered. The discrepancies and low reproducibility of the data observed between authors originate from various factors: (1) The starting material is different in all the cases. Some authors studied the solubility of ZnS using mineral ZnS from different origins [9]. Others performed the experiments with precipitated $\mathrm{ZnS}[3,4]$. In some cases the precipitate was obtained in-situ using different purification methods [13]. (2) It is questionable if equilibrium was reached. (3) The presence of oxygen also plays an important role in the measured value. There was no attempt of removing oxygen in some of the experiments; therefore oxidized species could have been formed and partially affect the measured solubility [9]. (4) The withdrawal of saturated solution in some cases does not occur at constant conditions (e.g. constant temperature). A particle size analysis was not carried out and used for selecting the pore size of the filter [13]. (5) Finally, the analytical techniques may not have been the most accurate for the determination of sparingly soluble salts e.g. gravimetric determination of the solubility implemented by [10] and the sensitivity of the radioactive tracer used by [14]. Some of the applied analytical techniques might also include the concentration of contaminants present in the solution [9]. 


\subsection{Reliability of the analytical technique and sampling method}

The reliability of the developed methodology for measurement of $\mathrm{ZnS}$ is assured by addressing the pitfalls observed in previous experimental methodologies. In this work there was a detailed focus toward the accuracy of the analytical technique applied for the concentrations measurements in water. The background noise of contaminants such as Zinc present in the ultra-pure water was measured. Blank samples (i.e. ultra-pure water) were analyzed by ICP-OES showing that the concentration of Zinc and total sulfur was below the detection limit $\left(4 \times 10^{-8}\right.$ $\mathrm{mol} \cdot \mathrm{kg}^{-1}$ for Zinc and $2 \times 10^{-7} \mathrm{~mol} \cdot \mathrm{kg}^{-1}$ for total sulfur). Therefore the content of total zinc and sulfur in the matrix of the samples does not constitute a source of noise in the measurements.

The error estimation of the measurements is determined using standard solutions of the elements studied here. The relative error estimated for zinc concentrations oscillates between 0.7 and $10.1 \%$. For total sulfur the error estimation oscillates between $0.6 \%$ and $5.7 \%$.

\section{Conclusions}

The solubility of $\mathrm{ZnS}$ in aqueous solution was determined at temperatures between $40{ }^{\circ} \mathrm{C}-80$ ${ }^{\circ} \mathrm{C}$ (atmospheric pressure). A dependency of the ZnS solubility on temperature was observed in

the interval of temperature studied. An increase of $40{ }^{\circ} \mathrm{C}$ results in an increase of roughly 12 times for the solubility of ZnS.

An experimental set-up was developed to measure the solubility of Zinc Sulfide (ZnS). This setup can be used for determination of low soluble salts solubility up to approximately $100{ }^{\circ} \mathrm{C}$ at atmospheric conditions for systems which tend to react with oxygen. The set-up and the developed methodology presented in this work address several drawbacks and pitfalls to be aware of during the analysis. These play a vital role in the previously published ZnS solubility measurements reported in literature.

The developed methodology prevents oxidation of the starting material and assures equilibrium conditions even during filtration of the saturated solution. 
The purity of our starting material was determined by SEM analysis, showing that the composition of the solid sample corresponds to high purity ZnS. A particle size analysis of the ZnS starting material was performed. This analysis is a key step during the determination of the ZnS solubility, allowing to choose the correct pore size for the filtration step. Equilibrium conditions were guaranteed by exploring a wide range of equilibration times (between 1 and 11 days). It is concluded that ZnS reaches equilibrium at around 3 days in contact by water. The scattering of the experimental data reported in this study could be due to presence of colloidal particles in the filtrate.

ICP-OES was applied as analytical technique. The relative error estimated for the measurements varies from $0.6 \%$ to $10.1 \%$, showing that ICP-OES is an adequate analytical technique for determination of ZnS solubility. The standard deviation calculated for each run demonstrates the very good precision of the implemented methodology.

During these experiments we observed that the evaporation of the aqueous phase plays a significant role in the solubility determination at high temperatures (above $80{ }^{\circ} \mathrm{C}$ ). We are currently building a high pressure/high temperature equipment to address this issue and to determine the individual effect of temperature and pressure on ZnS solubility. 


\section{References}

1. Savin, A.J., Adamson, B., Wylde, J.J., Kerr, J.R., Kayser, C.W., Trallenkamp, T., Fischer, D., Okocha, C.: Sulfide Scale Control: A High Efficacy Breakthrough Using an Innovative Class of Polymeric Inhibitors. SPE Int. Oilf. Scale Conf. Exhib. (2014).

2. Clever, H.L., Derrick, M.E., Johnson, S.A.: The solubility of some sparingly soluble salts of zinc and cadmium in water and in aqueous electrolyte solutions. J. Phys. Chem. Ref. data. 21, 941-1004 (1992).

3. Barrett, T.J., Anderson, G.M.: The solubility of sphalerite and galena in 1-5 $\mathrm{m} \mathrm{NaCl}$ solutions to 300 C. Geochim. Cosmochim. Acta. 52, 813-820 (1988).

4. Tagirov, B.R., Seward, T.M.: Hydrosul fi de / sul fi de complexes of zinc to $250^{\circ} \mathrm{C}$ and the thermodynamic properties of sphalerite. Chem. Geol. 269, 301-311 (2010).

5. Tagirov, B.R., Suleimenov, O.M., Seward, T.M.: Zinc complexation in aqueous sulfide solutions: Determination of the stoichiometry and stability of complexes via $\mathrm{ZnS}(\mathrm{cr})$ solubility measurements at $100{ }^{\circ} \mathrm{C}$ and 150 bars. Geochim. Cosmochim. Acta. 71, 49424953 (2007).

6. Barrett, T.J., Anderson, G.M.: The solubility of sphalerite and galena in $\mathrm{NaCl}$ brines. Econ. Geol. 77, 1923-1933 (1982).

7. Ewald, A.H., Hladky, G..: Solubility Measurements on Sphalerite. , North Ryde (NSW), Australia (1980).

8. Hayashi, K., Sugaki, A.: Solubility of sphalerite in aqueous sulfide solutions at temperatures between 25 and $240^{\circ} \mathrm{C} .54,3-5$ (1990).

9. Weigel, O.: The solubility of the sulphides of the heavy metals in water. Z. Phys. Chem. 58, 293-300 (1907).

10. Ellis, A.J.: The solubility of zinc sulfide in water at high temperatures. Econ. Geol. 54, 1035-1039 (1959). 
11. Laudise, R.A., Kolb, E.D., JP, D.: Hydrothermal solubility and growth of sphalerite. Am. Mineral. 50, 382 (1965).

12. Hemley, J.J., Meyer, C., Hodgson, C.J., Thatcher, A.B.: Sulfide solubilities in alterationcontrolled systems. Science (80-. ). 158, 1580-1582 (1967).

13. Vukotic, S.: Contribution to the study of the solubility of galena, of sphalerite, and of chalcopyrite in water in the presence of hydrogen sulfide between 50 and $200 \mathrm{C}$. Bull. Bur. Rech. Geol. Min. 11-27 (1961).

14. Relly, B.H.: A method for determining solubility at high temperatures and pressures. Econ. Geol. 54, 1496-1505 (1959).

15. Barnes, H..: Ore Solutions. Carnegie Institute of Washington (1958).

16. Villafáfila Garcia, A., Thomsen, K., Stenby, E.H.: Prediction of mineral scale formation in geothermal and oilfield operations using the extended UNIQUAC model: part I. Sulfate scaling minerals. Geothermics. 34, 61-97 (2005).

17. Børeng, R., Schmidt, T., Vikane, O., Tau, L.A., Dybdahl, B., Dale, T.I., Thowsen, O.: Downhole measurement of $\mathrm{pH}$ in Oil \& Gas Applications by use of a Wireline Tool. In: SPE European Formation Damage Conference. Society of Petroleum Engineers (2003).

18. OLI Systems Inc.: Electrolyte Simulation Software Tools, http://www.olisystems.com/.

19. Okocha, C.: Effects of Sulphide Scales ( PbS , ZnS \& FeS ) on BaSO4 Crystal Growth and Dissolution. Water. 96, (2010).

20. Kolthoff, I.M.: The Solubilities and Solubility Products of Metallic Sulphides in Water. J. Phys. Chem. 35, 2711-2721 (1931).

21. Potter, R.W., Clynne, M.A.: Solubility of highly soluble salts in aqueous media. Part 1. $\mathrm{NaCl}, \mathrm{KCl}, \mathrm{CaCl} 2, \mathrm{Na} 2 \mathrm{SO} 4$, and $\mathrm{K} 2 \mathrm{SO} 4$ solubilities to $100^{\circ} \mathrm{C}$. J. Res. US Geol. Surv.;(United States). 6, (1978). 
22. Jones, R.: Particle size analysis by laser diffraction: ISO 13320, standard operating procedures, and Mie theory. Am. Lab. 35, (2003).

23. Sampaio, R.M.M., Keesman, K.J., Lens, P.N.L.: Monitoring ZnS Precipitation: Estimation, Error Analysis and Experiment Design. (2009).

24. Luther, G.W., Theberge, S.M., Rickard, D.T.: Evidence for aqueous clusters as intermediates during zinc sulfide formation. Geochim. Cosmochim. Acta. 63, 3159-3169 (1999). 